\title{
Design Optimization of Integrated Rotor-less Inductors for High-Speed AC Drive Applications
}

\author{
M. Raza Khowja*, C. Gerada*+, G. Vakil*, C. Patel* and P. Wheeler*
}

\begin{abstract}
Discrete sub-system due to passive elements in motor drive require functional and structural integration to make efficient and power dense overall system. Such power dense system is the prerequisite in aerospace and marine applications. This paper presents the design optimization of integrated rotor-less inductors for high speed AC drive applications. Different slot-pole combinations are considered in this process. The single layer (SL) and double layer (DL) windings are chosen with concentrated winding $(\mathrm{CW})$ and distributed winding (DW) configurations. The rotor-less inductors are optimized and compared in this paper with $\mathrm{EE}$ core inductor in terms of total losses, weight and AC copper resistance at both fundamental frequency and switching frequencies $(10,15$ and $20 \mathrm{kHz})$. The comparative analysis between $\mathrm{EE}$ core and rotor-less inductors has shown a significant reduction in total losses and $\mathrm{AC}$ copper resistance at both fundamental frequency and all switching frequencies.
\end{abstract}

Index Terms - EE Core Inductor, Integrated Rotor-less Inductors, Concentrated winding and Distributed winding.

\section{INTRODUCTION}

$\mathrm{T}$ HE integration of passive elements such as capacitor, inductor or transformer is becoming more prevalent in the industry of power electronics and drives. Over the last few years, there has been a transformation from conventional separated passive components to integrated options enclosed within the drive system. The use of passive integration in motor drive applications offer many benefits such as compact design, reduction in cost, mass, size and fewer manufacturing process. Therefore, applications where high power density is needed, the use of the integrated options present to be the best solution [1-3].

The aim of this paper is to optimize the motor-shaped rotorless inductors proposed in [4] for high speed AC drives applications, focusing on reducing losses at both fundamental and switching frequencies. Different slot-pole combinations and winding arrangements are employed and compared with a conventional EE core inductor. 6, 12 and 18 slots with 2, 4 and 6 poles are considered. On the other hand, concentrated winding (CW) and distributed winding (DW) with single and double layers are considered.

All designs are modelled and analyzed through two dimensional finite element analysis (FEA). Since the effect of end winding inductance and end winding leakage flux is negligible compared to inductance and the leakage flux of the

M. Raza Khowja*, C. Gerada*+, G. Vakil*, C. Patel*, Pat Wheeler* are with the Power Electronics, Machines and Control Group. *PEMC Group, University of Nottingham, Nottingham, UK. +PEMC Group, University of Nottingham, Ningbo China. Email: Raza.Khowja@nottingham.ac.uk machine itself, the 3D finite element analysis has not been adopted in this paper.

\section{LITERATURE REVIEW}

The paper [4] proposed novel integrative options for passive filter inductor which includes: motor-shaped rotational and rotor-less inductor for high speed drives. Both inductor designs are integrated axially inside the motor housing which has resulted in shared cooling system. The iron losses are minimized in the rotational inductor design by rotating its rotor at synchronous speed. This makes it appropriate application for the inverter output filter.

On the other hand, the rotor-less inductor design is proposed to use as a high power line inductors or isolation transformers. Furthermore, the AC resistance due to skin and proximity effects is reduced dramatically when compared with the conventional EE core inductor.

In [5], a novel approach to integrate the inverter output filter inductor is presented for PMSM drives. The paper uses the inherent motor magnetics as filter inductance, introducing an external inductor instead. This leads to the elimination of power losses, weight and volume associated with an external filter inductor.

The design of integrated filter inductor for power factor correction application is presented in [6]. The paper modified the stator laminations to increase the stator back iron which act as an integrated filter inductor. This modification increases the outer diameter of the motor.

The complete stator back iron also can be used as magnetic component for one or more discrete inductors by integrating toroidal winding which drives alternating magnetic flux in the complete loops through the back iron of the stator core [7-8].

\section{INTEGRATED ROTOR-LESS INDUCTOR}

The integrated rotor-less inductor is shown in Fig. 1. The motor-shaped rotor-less inductor design is extensively different from traditional inductors. It has stator and rotor like conventional motor or generator but without any magnet, winding or saliency on rotor. This round shape allows the inductor to integrate within the motor by fitting it axially with motor stator.

Furthermore, inductor can share the same motor housing thus eliminating the requirement of separate cooling system. As the motor-shaped inductor uses the same cooling system as that of motor or generator, it can be operated with a higher current density that would result in to reduced overall size and weight of the inductor. 


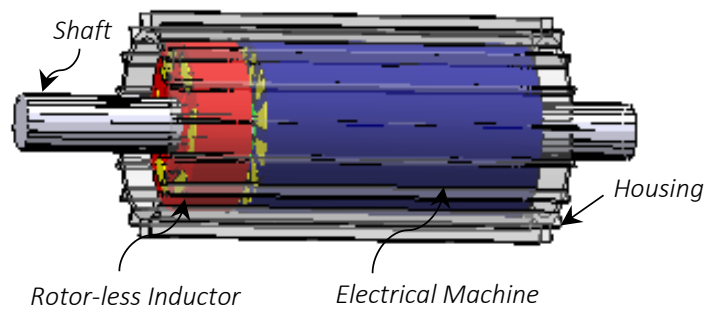

Fig.1: Integrated Motor-shaped Rotor-less Inductor

\section{WINDING CONFIGURATIONS}

In general, concentrated and distributed windings are the most widely used winding configurations for electrical machines. The CWs are wound together around each tooth to form a complete coil. The $\mathrm{CW}$ eliminates the need of large end winding lengths. This leads to a lower mean length per turn and hence reduces the copper losses in the end region of the windings [16-17].

However, CW induces lower mutual inductance compared to the DW which reduces the total inductance of the winding. This is due to the short pitching of the coils. The CW also induces harmonic components which lead to an increase in frequency dependent losses in the iron core such as hysteresis and eddy current loss [17].

The DWs are wound in multiple tooth and distributed throughout the stator periphery in either full-pitch or fractionalpitch arrangement. The DWs are distributed sinusoidal windings which leads to lower space harmonics induction and lower leakage flux [16].

The windings of a motor or generator can be single or double layer depending on the application of the machine. The side cross section of end winding length is shown in Fig. 2(a)(c). The practical implementation of the DW is having end winding length more than the single layer (SL) CW while on the other hand, double layer (DL) $\mathrm{CW}$ give the lowest end winding length and hence end winding copper loss.

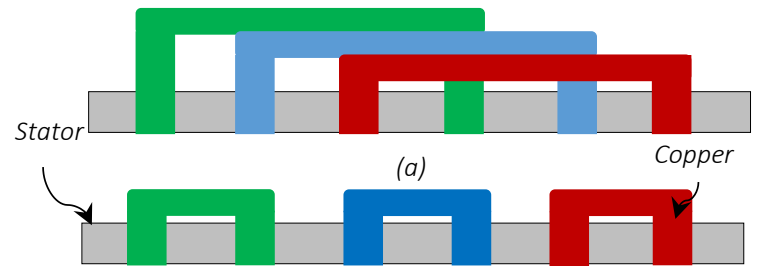

(b)

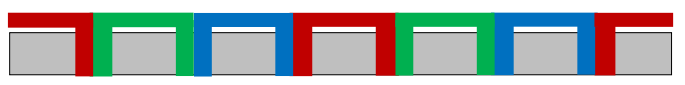

(c)

Fig. 2: Side cross section of end winding lengths (a) SL/DL DW (b) SL CW (c) DL CNW

\section{DESIGN OPTIMIZATION OF MOTOR-SHAPED INDUCTORS}

A number of motor-shaped inductors were designed, with a range of slot-pole combinations for integrated rotor-less inductors. The rotor-less inductors were optimized and then compare with conventional EE core inductor in terms of total losses, weight and AC copper loss.

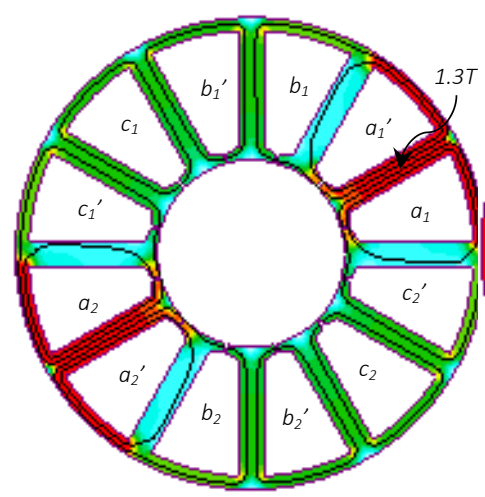

a)

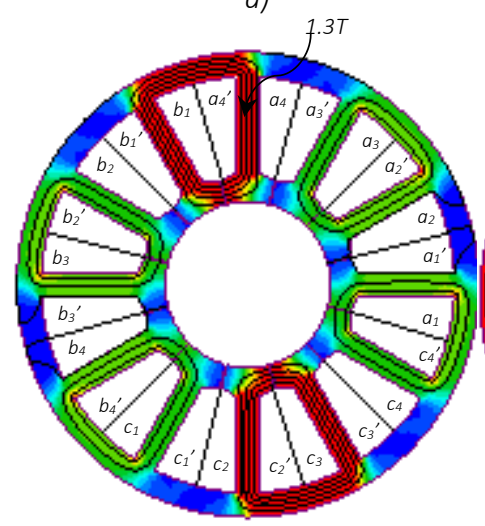

c)

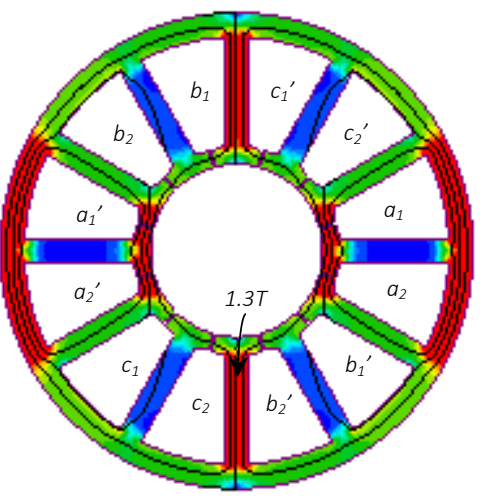

b)

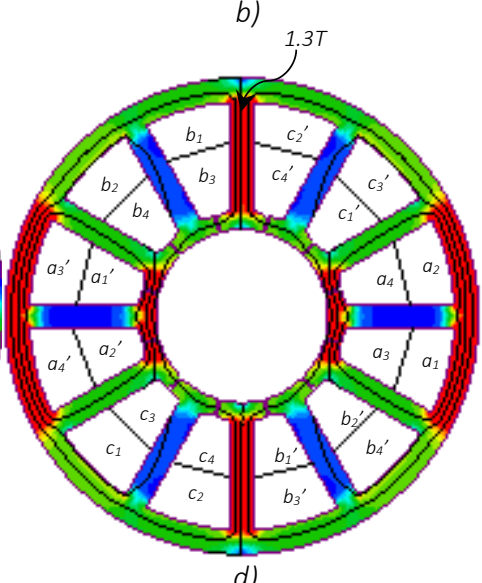

d)
Fig. 3: Winding Configuration of 12 Slots 2 Poles Combination (a) RL CW SL (b) RL DW SL (c) RL SNW DL (d) RL DW DL

6, 12 and 18 slots with 2,4 and 6 poles have been considered. On the other hand, CW and DW with single and double layers were chosen. All designs were modelled and analyzed through two dimensional finite element analyses (FEA). The flux distribution and winding configuration of 12 slots 2 Poles combination for rotor-less inductors are shown in Fig. 3(a)-(d).

EE core inductor is first designed [11] and then converted into motor-shaped inductors [4]. For the purpose of fair comparison, the type of core material, synchronous inductance, operating flux density, fundamental frequency, switching frequency, turns per slot, slot fill factor, slot area and conductor diameter were kept the same, the details of which are provided in Table I.

Initially, the DC copper loss without end windings and the inductor stack length were kept the same for the EE core inductor and motor-shaped inductors. Since the distributed windings give higher inductance than the CWs, the stack length of motor-shaped inductors was changed to keep the synchronous inductance same for all inductor designs.

The calculation of end winding length in this paper is approximated through an arc of the semi-circle as shown in Fig. 4. The total mean length per turn of a conductor is twice the sum of the stack length and the semicircle arc around the corner.

TABLE I: INDUCTOR DESIGN SPECIFICATIONS

\begin{tabular}{|c|c|c|}
\hline SPECIFICATIONS & VALUES & UNIT \\
\hline Magnetic Material & $\begin{array}{c}\text { Non Oriented Steel } \\
\mathrm{M}-1529 \mathrm{Ga}\end{array}$ & - \\
\hline
\end{tabular}




\begin{tabular}{|c|c|c|}
\hline Required Inductance & 1.3 & $\mathrm{mH}$ \\
\hline Operating Current & 18 & $\mathrm{~A}$ \\
\hline Operating Frequency & 1000 & $\mathrm{~Hz}$ \\
\hline Switching Frequencies & $10,15 \& 20$ & $\mathrm{kHz}$ \\
\hline Turns per slot & 20 & - \\
\hline Slot Fill Factor & 0.49 & - \\
\hline Slot Area & $2 \times 212$ & $\mathrm{~mm}-\mathrm{sq}$ \\
\hline Conductor Diameter & 2.6 & $\mathrm{~mm}$ \\
\hline RMS Current Density & 2.36 & $\mathrm{~A} / \mathrm{mm}^{2}$ \\
\hline Rotaional Inductor Shaft Diameter & 27 & $\mathrm{~mm}$ \\
\hline
\end{tabular}

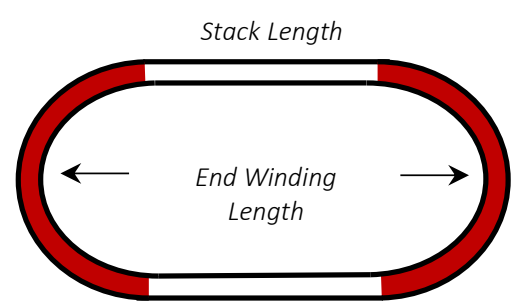

Fig. 4: Single Conductor with End Winding Length

The comparative analysis between EE core inductor and motor-shaped inductors with different slot-pole combination is presented in section IV (A)-(C). Single and double layer CW and DW are considered for each of the slot-pole combination.

\section{A. 2 Poles with 6, 12 and 18 slots Combination}

The motor-shaped rotor-less inductors are analyzed and compared with EE core inductor in terms of total losses, total and weight. The performance comparison of 2 poles (2P) rotorless inductor with 6,12 and 18 slots combination is presented in Table II. The total losses include: fundamental iron and copper losses with end winding length taken into account whereas, the total weight include the weight of the stator, rotor and windings of the inductor with end windings taking into account.

As can be observed from the Table II, the DW gives the higher inductance as compared to $\mathrm{CW}$. This is because; the full pitch arrangement of the distributed winding induces higher voltage across it. The short pitch arrangement of the $\mathrm{CW}$ resulted in a lower synchronous inductance.

The stack length comparison of the rotor-less inductor is also presented in Table II which is varied in proportion to the change in the synchronous inductance. The synchronous inductance is remain same for SL and DL design since changing from SL to DL does only affect the end winding length of the windings.

TABLE II: PERFORMANCE COMPARSION OF 2 POLES RotATION INDUCTOR WITH 6, 12 AND 18 SLOTS COMBINATION

\begin{tabular}{|c|c|c|c|c|c|}
\hline SLOTS & $\begin{array}{c}\text { EE } \\
\text { Core }\end{array}$ & $\begin{array}{c}\text { RL CW } \\
\text { SL }\end{array}$ & $\begin{array}{c}\text { RL DW } \\
\text { SL }\end{array}$ & $\begin{array}{c}\text { RL CW } \\
\text { DL }\end{array}$ & $\begin{array}{c}\text { RL DW } \\
\text { DL }\end{array}$ \\
\hline \multicolumn{7}{|c|}{ Total Losses (W) } \\
\hline 6 & 151.4 & 128.8 & 146.4 & 244.9 & 179.1 \\
\hline 12 & 151.4 & 143.7 & 92.8 & 303.4 & 96.3 \\
\hline 18 & 151.4 & 144.5 & 84 & 433.1 & 84 \\
\hline \multicolumn{7}{|c|}{ Total Weight (Kg) } \\
\hline 6 & 2.28 & 2.63 & 2.27 & 3.6 & 2.21 \\
\hline 12 & 2.28 & 3.05 & 2.44 & 6.32 & 2.77 \\
\hline
\end{tabular}

\begin{tabular}{|c|c|c|c|c|c|}
\hline 18 & 2.28 & 3.8 & 3.51 & 9.77 & 3.51 \\
\hline \multicolumn{7}{|c|}{ Synchronous Inductance $(\mathrm{mH})$} \\
\hline 6 & 1.3 & 1.3 & 2.3 & 1.3 & 2.3 \\
\hline 12 & 1.3 & 1.39 & 2.81 & 0.81 & 2.79 \\
\hline 18 & 1.3 & 1.43 & 3.41 & 0.66 & 3.41 \\
\hline \multicolumn{7}{|c|}{ Stack Length (mm) } \\
\hline 6 & 114.5 & 114.5 & 64.7 & 114.5 & 64.7 \\
\hline 12 & 114.5 & 107.1 & 52.94 & 183.8 & 53.4 \\
\hline 18 & 114.5 & 104 & 43.6 & 225.2 & 43.6 \\
\hline
\end{tabular}

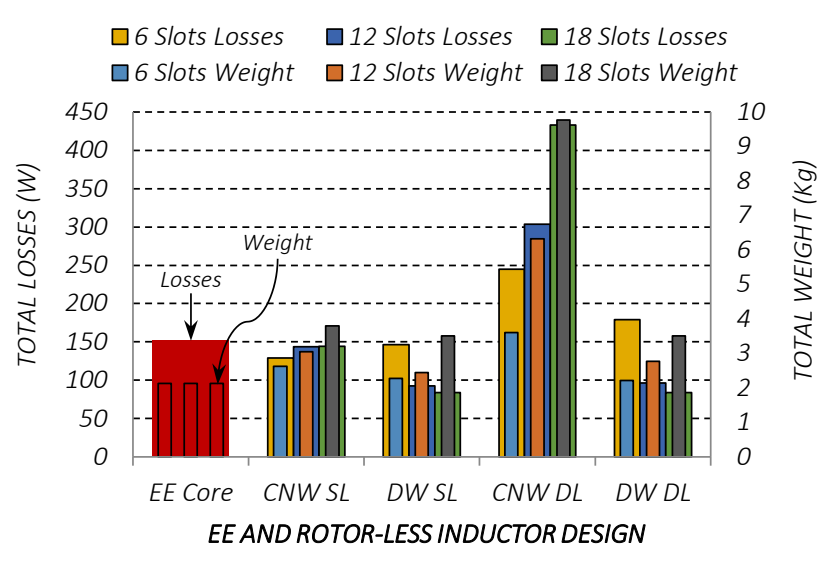

Fig.5: Comparison of 2 Poles Rotor-less Inductor with 6, 12 and 18 Slots

In comparison with EE inductor, the most efficient inductor design in 2 poles combination is 18 slots DW rotor-less inductor with both SL and DL. The total losses reduction in 18 slots rotor-less inductor with DL DW is $44.5 \%$ when compared with EE core inductor. In general, 12 slots rotor-less inductor contributes better performance in terms of total losses and weight. For 12 slots rotor-less inductor, the total losses are reduced from $151.4 \mathrm{~W}$ to $92.8 \mathrm{~W}$, which is $39 \%$ reduction. The weight of the rotor-less inductors are relatively higher than the $\mathrm{EE}$ core inductor due to the full pitch arrangement of the DW, the details of which is provided in Table II.

Moreover, the $\mathrm{CW}$ requires higher stack length to meet the inductance requirement which in turn increases the total losses and weight of the inductor. The comparison of the total losses and weight between EE and rotor-less inductor with 6,12 and 18 slots combination is shown in Fig. 5.

\section{B. 4 Poles with 6, 12 and 18 slots Combination}

The performance comparison of 4 poles (4P) rotor-less inductor with 6, 12 and 18 slots combination is presented in Table III. Again, it can be observed from the Table III, the SL DW gives the higher inductance as compared to $\mathrm{CW}$ due to different winding arrangements. The DL DW also gives the higher inductance than DL CW in 12 and 18 slots inductors whereas the inductance remain unchanged in DL DW and CW for 6 slots inductor.

TABLE III: PERFORMANCE COMPARSION OF 4 POLES RotATION INDUCTOR WiTh 6, 12 AND 18 SLOTS COMBINATION

\begin{tabular}{|c|c|c|c|c|c|}
\hline SLOTS & $\begin{array}{c}\text { EE } \\
\text { Core }\end{array}$ & $\begin{array}{c}\text { RL CW } \\
\text { SL }\end{array}$ & $\begin{array}{c}\text { RL DW } \\
\text { SL }\end{array}$ & $\begin{array}{c}\text { RL CW } \\
\text { DL }\end{array}$ & $\begin{array}{c}\text { RL DW } \\
\text { DL }\end{array}$ \\
\hline \multicolumn{7}{|c|}{ Total Losses (W) } \\
\hline 6 & 151.4 & - & - & 196.1 & 197.5 \\
\hline 12 & 151.4 & 117.3 & 114.5 & 192.4 & 112.6 \\
\hline
\end{tabular}




\begin{tabular}{|c|c|c|c|c|c|}
\hline 18 & 151.4 & - & - & 225.1 & 98.1 \\
\hline \multicolumn{7}{|c|}{ Total Weight (Kg) } \\
\hline 6 & 2.28 & - & - & 2.31 & 2.39 \\
\hline 12 & 2.28 & 3.22 & 2.61 & 3.78 & 2.58 \\
\hline 18 & 2.28 & - & - & 5.34 & 3.14 \\
\hline \multicolumn{7}{|c|}{ Synchronous Inductance (mH) } \\
\hline 6 & 1.3 & - & - & 1.16 & 1.16 \\
\hline 12 & 1.3 & 1.3 & 2.56 & 1.3 & 2.59 \\
\hline 18 & 1.3 & - & - & 1.3 & 3.52 \\
\hline \multicolumn{7}{|c|}{ Stack Length (mm) } \\
\hline 6 & 114.5 & - & - & 128.2 & 128.2 \\
\hline 12 & 114.5 & 114.5 & 58.1 & 114.5 & 57.4 \\
\hline 18 & 114.5 & - & - & 114.5 & 42.3 \\
\hline
\end{tabular}

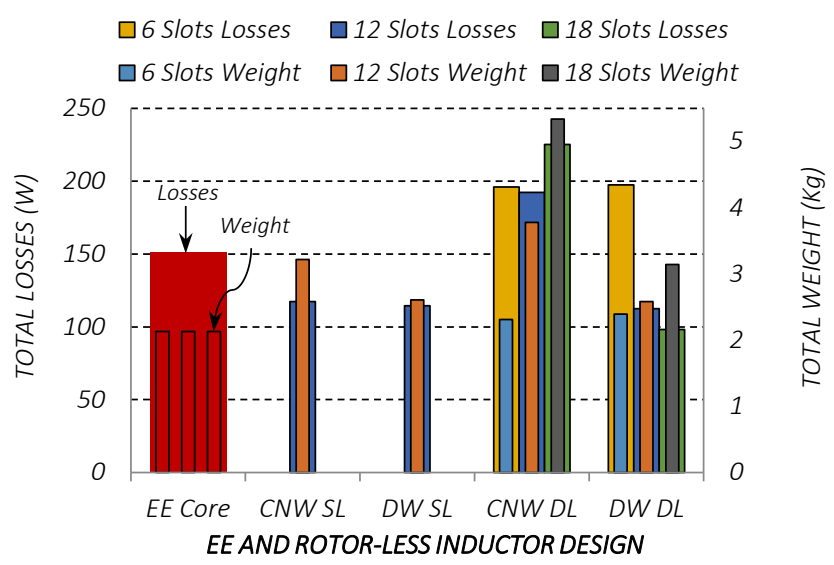

Fig. 6: Comparison of 4 Poles Rotor-less Inductor with 6, 12 and 18 Slots

As stated earlier, the stack length is varied in proportion to the change in the synchronous inductance, the new stack length of the inductors in shown in Table III. The synchronous inductance and hence stack length is remain unchanged for SL and DL design.

In comparison with EE inductor, the most efficient inductor design in 4 poles combination is DL 18 slots rotor-less inductor with DW. For 18 slots rotor-less inductor with DL DW, the total losses are reduced from $151.4 \mathrm{~W}$ to $98.1 \mathrm{~W}$, which is $35.1 \%$ reduction. The comparison of the total losses and weight between $\mathrm{EE}$ and rotor-less inductor with 6,12 and 18 slots combination is shown in Table III and Fig. 6.

\section{6 Poles with 6, 12 and 18 slots Combination}

The performance comparison of 6 poles (6P) rotor-less inductor with 18 slots is presented in Table IV. The 6 and 12 slots winding are not feasible in the case of 6 poles. It can be seen in Table IV that the SL and DL DW gives the higher inductance as compared to $\mathrm{CW}$.

The new stack length is changed in in accordance with the synchronous inductance. The most efficient design in 6 poles combination is 18 slots rotor-less inductor with both SL DW and DL DW with relatively higher weight. The total losses are reduced from $151.4 \mathrm{~W}$ to $122 \mathrm{~W}$, which is $19.4 \%$ reduction. The comparison of the total losses and weight between EE and rotor-less inductor with 6,12 and 18 slots combination is shown in Table VI and Fig. 7.
TABLE IV: PERFORMANCE COMPARSION OF 6 POLES RotATION INDUCTOR WITH 18 SLOTS COMBINATION

\begin{tabular}{|c|c|c|c|c|c|}
\hline PARAMETERS & $\begin{array}{c}\text { EE } \\
\text { Core }\end{array}$ & $\begin{array}{c}\text { RL CW } \\
\text { SL }\end{array}$ & $\begin{array}{c}\text { RL DW } \\
\text { SL }\end{array}$ & $\begin{array}{c}\text { RL CW } \\
\text { DL }\end{array}$ & $\begin{array}{c}\text { RL DW } \\
\text { DL }\end{array}$ \\
\hline $\begin{array}{c}\text { Total } \\
\text { Losses (W) }\end{array}$ & 151.4 & 124.7 & 122 & 201.2 & 122.1 \\
\hline $\begin{array}{c}\text { Total } \\
\text { Weight (Kg) }\end{array}$ & 2.28 & 3.81 & 2.73 & 3.96 & 2.81 \\
\hline $\begin{array}{c}\text { Synchronous } \\
\text { Inductance (mH) }\end{array}$ & 1.3 & 1.45 & 2.95 & 1.45 & 2.95 \\
\hline $\begin{array}{c}\text { Stack } \\
\text { Length (mm) }\end{array}$ & 114.5 & 102.7 & 50.5 & 103.4 & 50.5 \\
\hline
\end{tabular}

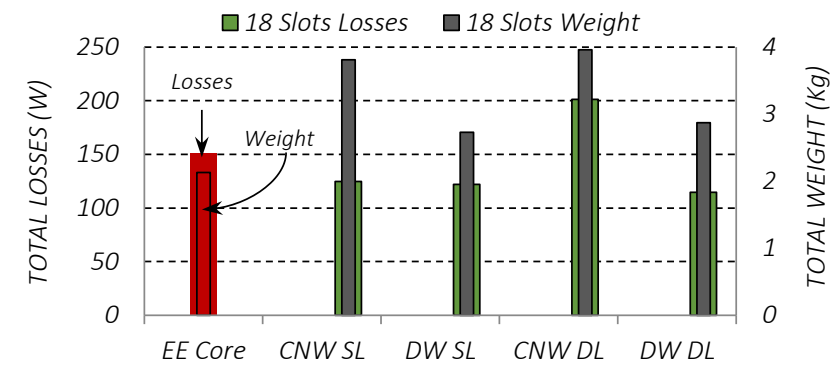

EE AND ROTOR-LESS INDUCTOR DESIGN

Fig. 7: Comparison of 6 Poles Rotor-less Inductor with 6, 12 and 18 Slots

\section{Short Thermal Analysis}

A thermal equivalent network has been made using a method of [12] is adopted to check the temperature rise of EE core and rotor-less inductors, the results of which are illustrated in Table V. Two most efficient rotor-less inductor designs have been chosen and compared with EE core inductor i.e. 12 slots 2 poles (DW SL) and 18 slots 2 poles (CW SL). As can be seen from Table $\mathrm{V}$ that rise in temperature of $\mathrm{EE}$ core inductor is higher than rotor-less inductors due to higher loss dissipation as compared to rotor-less inductors.

TABLE V: COMPARISON OF TEMPERATURE RISE

\begin{tabular}{|c|c|c|c|c|}
\hline & $\begin{array}{c}\text { EE } \\
\text { Core }\end{array}$ & $\begin{array}{c}12 \mathrm{~S} 2 \mathrm{P} \\
\text { DW SL }\end{array}$ & $\begin{array}{c}18 \mathrm{~S} 2 \mathrm{P} \\
\text { DW SL }\end{array}$ & UNIT \\
\hline Back Iron & 5.1 & 1.2 & 1.3 & ${ }^{\circ} \mathrm{C}$ \\
\hline Teeth & 5.3 & 1 & 1.5 & ${ }^{\circ} \mathrm{C}$ \\
\hline Windings & 5.5 & 1.3 & 1.8 & ${ }^{\circ} \mathrm{C}$ \\
\hline
\end{tabular}

\section{E. Comparsion of AC Loss}

The best inductor designs were selected from the performance comparison of rotor-less inductors and the AC copper loss had been assessed and compared with EE core inductor. The inductors have been chosen from each of the slot combination with 2 poles as 2 poles stator windings contributes the lowest leakage flux. The chosen inductor designs are: 6 slots (6S) 2P CW SL, 12 slots (12S) 2P DW SL, 18 slots (18S) 2P DW SL.

To evaluate the AC copper loss at fundamental and switching frequency (FSW), individual solid conductors were modelled. The current densities of selected inductor designs, when phase A reaches its peak value are shown in Fig. 8(a)-(d). The magnitude of the harmonic component is considered to be $5 \%$ of the fundamental for determining and analyzing the $\mathrm{AC}$ 
copper loss. The fundamental current with switching frequency components were injected into the FEA model. The injected current waveforms are shown in Fig. 9(a)-(c). The relation between the DC and AC copper loss is given by,

$$
P_{\text {copper }}=P_{d c}+P_{a c}
$$

where,

$P_{\text {copper }}$ is the total copper losses,

$P_{d c} \quad$ is the DC copper loss with end winding effect taking into account and

$P_{a c} \quad$ is the AC copper loss due to skin and proximity effect where end winding AC copper loss effect is neglected.

The AC copper loss in EE core inductor is observed higher than that of rotor-less inductors at fundamental and all considered switching frequencies, results of which are shown in Table VI. 6S rotor-less inductor with SL CW gives the lowest AC copper loss at both fundamental frequency and switching frequencies of 10,15 and $20 \mathrm{kHz}$ amongst all the inductor design. For 6S 2P SL CW, the AC loss reduction of $53.7 \%$ is achieved at fundamental frequency, whereas the reduction of $59.5 \%, 59.8$ and $60.1 \%$ is achieved at all switching frequencies respectively, when compared with the EE core inductor. $12 \mathrm{~S} 2 \mathrm{P}$ rotor-less inductor with SL DW does not offer AC loss reduction at fundamental frequency, whereas the reduction of $12.3 \%, 15.8$ and $16.4 \%$ is achieved at all considered switching frequencies respectively.

On the other hand, $18 \mathrm{~S} 2 \mathrm{P}$ rotor-less inductor with SL DW is unable to provide AC copper loss reduction due to higher leakage and fringing fluxes around the stator slots opening. This is due to the smaller shaft diameter which is kept identical for all the inductor designs. Moreover, the number of conductors per phase are higher for $12 \mathrm{~S}$ and $18 \mathrm{~S}$ inductors which leads to lower AC copper loss reduction compared to $6 \mathrm{~S}$ inductor.

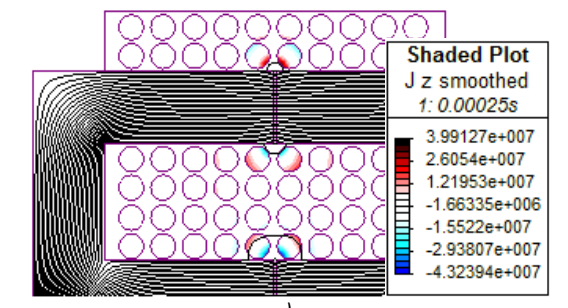

a)
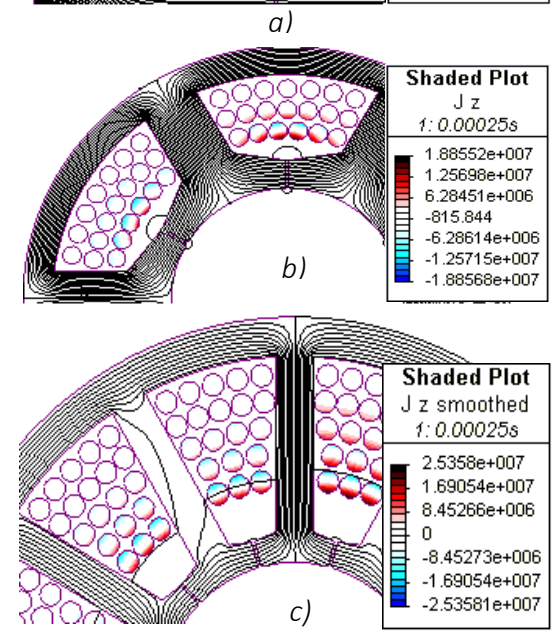

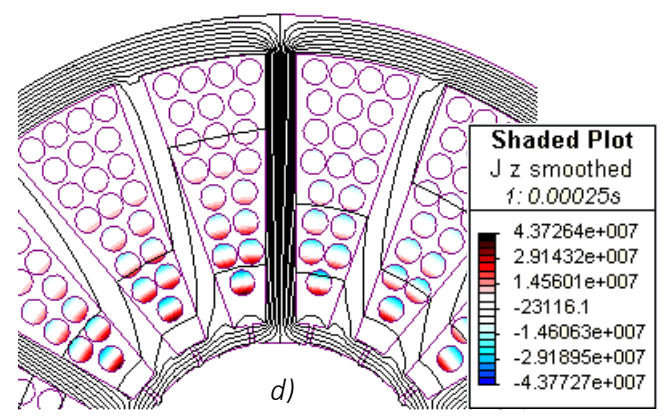

Fig. 8: Effect of Leakage and Fringing Flux at $1000 \mathrm{~Hz}$ for EE and Rotor-less Inductors (a) EE Core (b) 2P 6S CW SL (c) 2P 12S DW SL (d) 2P 18S DW SL

It is important to note that most of the conductors are placed close to the airgap in EE design which has resulted in more fringing effect. In contrast, conductors of $6 \mathrm{~S}$ rotor-less inductor are placed far from the slot opening airgap therefore, experiencing less fringing flux cutting the conductors. The effect of leakage flux is likewise lesser in the rotor-less inductor as its slot width is wider than the window width of the EE inductor. The effect of fringing and leakage fluxes is the reason for more flux cutting the conductors thus increasing the AC resistance, and hence, AC copper loss at both fundamental and all switching frequencies.

TABLE VI: COMPARISON OF AC COPPER LOSS

\begin{tabular}{|c|c|c|c|c|c|}
\hline $\begin{array}{c}\text { FSW } \\
(\mathbf{k H z})\end{array}$ & EE Core & $\begin{array}{c}\text { 6S 2P } \\
\text { CW SL }\end{array}$ & $\begin{array}{c}\text { 12S 2P } \\
\text { DW SL }\end{array}$ & $\begin{array}{c}\text { 18S 2P } \\
\text { DW SL }\end{array}$ & UNIT \\
\hline 1 & 17.49 & 8.10 & 17.49 & 52.91 & $\mathrm{~W}$ \\
\hline 10 & 1.42 & 0.57 & 1.24 & 4.07 & $\mathrm{~W}$ \\
\hline 15 & 1.98 & 0.80 & 1.67 & 5.90 & $\mathrm{~W}$ \\
\hline 20 & 2.47 & 0.99 & 2.06 & 7.43 & $\mathrm{~W}$ \\
\hline
\end{tabular}

a)

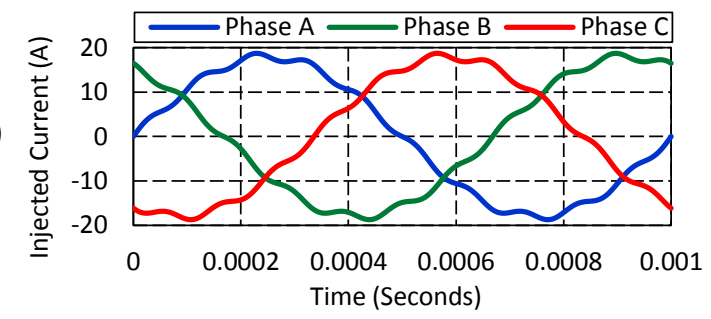

b)

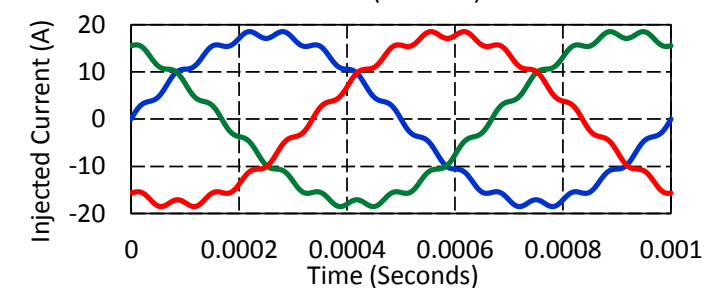

c)

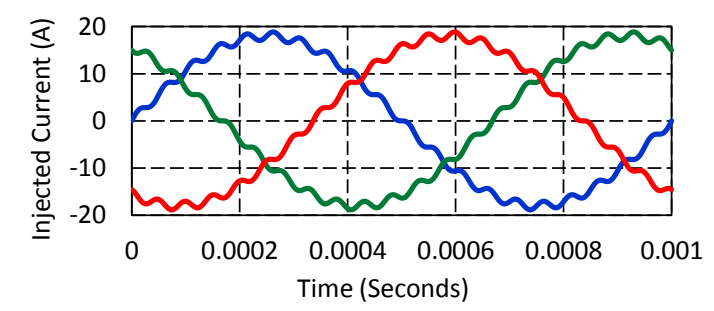

Fig. 9: Injected current with FSW (a) $10 \mathrm{kHz}$ (b) $15 \mathrm{kHz}$ (c) $20 \mathrm{kHz}$ 


\section{CONCLUSIONS}

A number of integrated rotor-less inductors were designed and proposed in this paper with different slot-pole combinations with single and double layer concentrated and distributed winding. The rotor-less inductors were optimized and then compared with EE core inductor in terms of total losses, weight and $\mathrm{AC}$ resistance at fundamental and all switching frequencies. The comparative analysis between $\mathrm{EE}$ core and rotor-less inductors has shown a significant reduction in total losses and $\mathrm{AC}$ resistance at both fundamental and switching frequencies.

For 12 slots 2 poles rotor-less inductor with SL DW, the total losses at fundamental frequency was reduced by $39 \%$ compared to EE core inductor. This comes at the expense of $7 \%$ increase in weight. For 18 slots 4 poles rotor-less inductor with SL DW, the total losses at fundamental frequency was reduced by $35.1 \%$ compared to EE core inductor. This comes at the expense of $37.7 \%$ increase in weight. For 18 slots 6 poles rotorless inductor with SL DW, the total losses at fundamental frequency was reduced by $19.4 \%$ compared to $\mathrm{EE}$ core inductor. This comes at the expense of $19.7 \%$ increase in weight.

Moreover, the AC loss at fundamental and all switching frequencies were reduced significantly when compared with EE core inductor. $6 \mathrm{~S}$ inductor with SL DW contributed the lowest $\mathrm{AC}$ copper loss at both fundamental frequency and switching frequencies of 10,15 and $20 \mathrm{kHz}$ amongst all the inductor design. For 6S 2P SL DW, the AC loss reduction of 53.7\% was achieved at fundamental frequency, whereas the reduction of $59.5 \%, 59.8$ and $60.1 \%$ is achieved at all switching frequencies respectively, when compared with the EE core inductor. $12 \mathrm{~S} 2 \mathrm{P}$ rotor-less inductor with SL DW had not offered AC loss reduction at fundamental frequency, whereas the reduction of $12.3 \%, 15.8$ and $16.4 \%$ is achieved at all considered switching frequencies respectively compared to the EE core inductor.

\section{REFERENCES}

[1] Robert Abebe, Gaurang Vakil, Giovanni Lo Calzo, Thmas Cox, Simon Lambert, Mark Johnson, Chris Gerada, Barrie Mecrow "Integrated motor drives: state of the art and future trends" IET Electric Power Applications, 15 pp, Print ISSN 1751-8660, Online ISSN 1751-8679

[2] Popovic-Gerber Jelena, Gerber M, Ferreira Braham "Integrated filter in electrolytic capacitor technology for implementation in high power density idustrial drives" Power Electronics Specialists Conference, 2008. PESC 2008. IEEE. Publication Year: 2008 , Page(s): 2968 - 2974

[3] Popovic J, Ferreira J.A, Gerber M.B, Konig A, de Doncker, R. "Integration technologies for high power density power electronic converters for AC drives". Power Electronics, Electrical Drives, Automation and Motion, 2006. SPEEDAM 2006. Publication Year: 2006 , Page(s): 634 - 639

[4] M. Raza Khowja, C. Gerada, G. Vakil, P. Wheeler and C. Patel "Novel Itegraive Options for Passive Filter Inductor in High Speed AC Drives" Industrial Electronics Society, IECON 2016 - 42 ${ }^{\text {nd }}$ Annual Conference of IEEE [5] M. Raza Khowja, C. Gerada, G. Vakil, P. Wheeler and C. Patel "Integrated Output Filter Inductor for Permanent Magnet Motor Drives" Industrial Electronics Society, IECON 2016 - 42 $2^{\text {nd }}$ Annual Conference of IEEE [6] Nee B.M, Chapman P.L. "Integrated Filter Element in Electric Drives" Vehicle Power and Propulsion Conference, 2007. VPPC 2007. IEEE. Publication Year: 2007 , Page(s): 148 - 153

[7] Garvey S.D. Norris, W.T, Wright M.T. "The role of integrated components in protecting motor windings". Electric Power Applications, IEEE Proceedings - Volume: 147 , Issue: 5 Publication Year: 2000

[8] Nakajima, Yuki Imazu, Tomoya Mizukoshi, Yukio Sato, Sho Zushi, Yusuke “Integrated Capacitor Type Stator”, Patent No. 8049383
[9] Adam Walker, Micheal Galea, Chris Gerada, Abdeslam Mebarki, David Gerada "Design Considerations for High Performance Traction Machines: Aiming for the FreedomCar 2020 Targets" 2015 International Conference on Electrical Systems for Aircraft, Railway, Ship Propulsion and Road Vehicles (ESARS). Year: 2015 Pages: 1-6

[10] Lester Chong, Rukmi Dutta, Nguyen Quang Dai, M. F. Rahman, Howard Lovatt "Comparison of Concentrated and Distributed Windings in an IPM Machine for Field Weakening Applications" Universities Power Engineering Conference (AUPEC), 2010 20th Australasian. Year: 2010 Pages: 1-5

[11] Kazimierczuk M.K, Sekiya H. "Design of AC resonant inductors using area product method" Energy Conversion Congress and Exposition, 2009. ECCE 2009. IEEE Publication Year: 2009

[12] P. H. Mellor, D. Roberts and D. R. Turner, "Lumped parameter thermal model for electrical machines of TEFC design," in IEE Proceedings B - Electric Power Applications, vol. 138, no. 5, pp. 205-218, Sept. 1991.

\section{BIOGRAPHIES}

Muhammad Raza Khowja received the BEng (Hons) degree in Electrical Engineering from Mehran University of Engineering \& Technology, Jamshoro, Pakistan, in 2011. He received his MSc degree in Electrical Engineering in 2012 from The University of Nottingham where he is currently working toward the $\mathrm{Ph}$.D. degree and working as a part time 'Research Associate' in the Power Electronics, Machines, and Control (PEMC) Group. His main research interest are: design of electrical machines and integration of passive components in motor drive system.

Chris Gerada (M'05) received the Ph.D. degree in numerical modeling of electrical machines from The University of Nottingham, Nottingham, U.K., in 2005. He subsequently worked as a Researcher with The University of Nottingham on high performance electrical drives and on the design and modeling of electromagnetic actuators for aerospace applications. Since 2006, he has been the Project Manager of the GE Aviation Strategic Partnership. He became a Lecturer in electrical machines in 2008, an Associate Professor in 2011, and a Professor in 2013 at The University of Nottingham. His main research interests include the design and modeling of high-performance electric drives and machines. Prof. Gerada serves as an Associate Editor for the IEEE TRANSACTIONS ON INDUSTRY APPLICATIONS and is the Chair of the Electrical Machines Committee of the IEEE Industrial Electronics Society.

Gaurang Vakil (M'16) received Ph.D. from Power Electronics, Machines and Drives (PEMD) group at Indian Institute of Technology - Delhi (IITD) in variable speed generator design for renewable energy applications in 2016 . He subsequently worked as a Research Associate with Power Electronics, Machines and Controls (PEMC) group at the University of Nottingham. In 2016 he was appointed as an assistant professor with electrical and electronics engineering department in University of Nottingham. His main research interests include analytical modelling and design optimization of electrica machines, optimizing electric drive-train for pure electric and hybrid vehicles, high power density machines, magnetic material characterization and highperformance electrical machines for transport and renewable generation.

Chintan Patel (S'08-M'12) received the Ph.D. degree from the Centre for Electronics Design and Technology, Indian Institute of Science, Bangalore, India, in 2011. He has been a Research Fellow with the Power Electronics, Machines and Control Group, The University of Nottingham, Nottingham, U.K., since March 2011. His current research interests include applications of power electronic converters for electromechanical actuation and aircraft electrical power systems.

Patrick W. Wheeler (M'00-SM'13) received the B.Eng. (Hons.) degree in 1990 and the Ph.D. degree in electrical engineering for his work on matrix converters in 1994, both from the University of Bristol, Bristol, U.K. In 1993, he moved to The University of Nottingham, Nottingham, U.K., where he was a Research Assistant with the Department of Electrical and Electronic Engineering and became a Lecturer with the Power Electronics, Machines and Control Group in 1996. Since January 2008, he has been a Full Professor in the same research group. He is currently the Head of the Department of Electrical and Electronic Engineering, The University of Nottingham. $\mathrm{He}$ has authored/coauthored 400 academic publications in leading international conference proceedings and journals. Prof. Wheeler is a Member at Large and a Distinguished Lecturer of the IEEE Power Electronics Society. 